\title{
An Empirical Study on the Segmentation of Potential Users of Shared Parking Spaces considering Individual Heterogeneity
}

\author{
Ange Wang $\mathbb{D}^{1},{ }^{1}$ Hongzhi Guan $\mathbb{D}^{1},{ }^{1}$ Jun Guo, ${ }^{1}$ Yan Han $\mathbb{D}^{2},{ }^{2}$ and Hangjin Bian ${ }^{1}$ \\ ${ }^{1}$ Faculty of Urban Construction, Beijing University of Technology, Beijing 100124, China \\ ${ }^{2}$ Beijing Key Laboratory of Traffic Engineering, Beijing University of Technology, Beijing 100124, China \\ Correspondence should be addressed to Yan Han; hanyan422@bjut.edu.cn
}

Received 21 October 2021; Revised 26 November 2021; Accepted 30 December 2021; Published 11 January 2022

Academic Editor: Ziyuan Pu

Copyright (c) 2022 Ange Wang et al. This is an open access article distributed under the Creative Commons Attribution License, which permits unrestricted use, distribution, and reproduction in any medium, provided the original work is properly cited.

Shared parking has become the most effective way to utilize existing parking resources. Little attention has been focused on drivers' intention to use shared parking spaces in residential areas considering individual heterogeneity. To fill this gap, this paper explores the influencing factors and mechanism of shared parking use intention (SPUI) and further studies the preferences for the shared parking of different types of drivers. Firstly, based on the extended unified theory of acceptance and use of technology that includes psychological factors, personal attributes, and travel characteristics, the multiple indicator multiple cause (MIMIC) model was employed for parameter estimation and model assessment. Secondly, using MIMIC's output results as input variables, the segmentation method of the latent class model (LCM) was adopted to explore drivers' preferences regarding SPUI. Finally, a quantitative study was carried out through questionnaire data. The empirical results show that: (a) the extended unified theory of acceptance and use of technology has good explanatory power for SPUI. SPUI is directly affected by perceived risk (PR), behavioral habit (BH), social influence (SI), facilitating conditions (FCs), and effort expectancy (EE), while performance expectancy (PE) have no significant effect on SPUI. In addition, some factors of personal attributes and travel characteristics affect SPUI through psychological factors. (b) According to individual heterogeneity, the surveyed driver groups are divided into four segments: sensitive type (36\%), conservative type (29.6\%), neutral type (24.5\%), and approved type (9.9\%), respectively. There are significant differences in psychological observation variables such as EE, PE, FC, and SI among the four segments of drivers. According to the influence mechanism of psychological factors and preferences analysis of different types of drivers, the shared parking promotion strategy can be formulated from the aspects of management, operation, and technology.

\section{Introduction}

With the rapid growth of car ownership, the contradiction between the increasing demand for parking and the limited parking resources has become more and more prominent. Until July 2020, China's parking space gap has reached 80 million $[1,2]$, which increases search time for parking and creates exhaust emissions and traffic congestions [3-5]. In addition, in the context of COVID-19, travelers are more worried about the safety of public transportation, and the government has adopted a series of antiepidemic measures, such as restricting the passenger capacity of public transportation, which has led to a further decrease in the proportion of citizens taking public transportation and an increase in the proportion of private car trips. Therefore, the contradiction between the supply and demand of parking spaces is further aggravated.

In recent years, the development of the sharing economy has been in full swing and has penetrated into many areas, such as shared cars(Evcard, Gofun), shared accommodation(Airbnb), and ridesharing (Lyft). Parking space has the characteristics of being nonstorable in time and nonmovable in space; besides, the parking demands also vary depending on land properties, so parking demands and spaces are not well matched. Therefore, the concept of shared parking has been proposed; the basic idea of the concept is that the parking space owners sell parking permits for the idle period of their parking space on the network 
platform, and drivers with parking demands can purchase parking permits through the network platform [6].

Residents' travel characteristics (often come out early and return late) make the parking spaces in the residential area idle during working hours, which makes the parking spaces in the residential area sharing during the working hours become possible. The number of parking spaces in residential areas accounts for a large proportion of the total number of parking spaces. According to the statistics of the Hong Kong Transport Department (2016), there are 485,000 parking spaces in Hong Kong (70\% of the total number of parking spaces are designated for private use). In addition, Yan et al. [7] pointed out that from 2015 to 2019, residential parking resources in Beijing accounted for an average of $53.16 \%$ of all parking resources, and nearly 800,000 private parking spaces were idle during working hours. A simulation experiment shows that if 20\% of Beijing's existing parking spaces are added to the sharing projects, carbon dioxide emissions can be reduced by 7.3 million tons per year [8]. Therefore, if the idle time of the huge number of parking spaces in residential areas can be fully utilized, the utilization rate of parking spaces can be effectively increased, and traffic congestion and carbon emissions can be further alleviated [9].

Shared parking projects are mainly concentrated in commercial areas in China, while shared parking projects in residential areas are very rare, and the participation is low; the fundamental reason is that drivers' SPUI is not strong [10]. Therefore, it is necessary to explore the drivers' SPUI. In addition, it is worth noting that because of the different sensitivities of drivers to the influencing factors, their performance is different and thus has different effects on the implementation of policy measures [11]. Generally, a segmentation study of travelers is helpful to estimate the differences in their behavior rules and characteristics, to classify travelers with taste heterogeneity, and then to formulate more targeted and effective policy measures [12]. Regarding taste heterogeneity, it has recently received considerable attention in the transportation field [13-15]. To the best of our knowledge, there is a lack of attention to revealing heterogeneity with respect to SPUI although some scholars have studied the SPUI from the perspective of demanders $[10,16]$, meaning that it would be certainly worthwhile to unveil how the impacts of the variables vary depending on individual heterogeneity as one of the first scientific efforts, adding knowledge to the literature.

This study aims to investigate the intention of drivers to use shared parking spaces in residential areas considering individual heterogeneity. Specifically, it firstly expands the unified theory of the acceptance and use of technology model and uses the extended unified theory of acceptance and use of technology as the theoretical framework. Then, a multiple indicator multiple cause (MIMIC) model is employed for parameter estimation and model assessment to characterize the intention of drivers toward the use of parking space sharing systems. Secondly, based on the results of the MIMIC model, the segmentation method of the latent class model (LCM) was adopted to explore drivers' preferences regarding SPUI, and the selection preferences of different types of drivers are analyzed according to psychological factors, demographic attributes, and travel characteristics, which will help to clarify the nature of SPUI at a deeper level and to formulate targeted inducement measures based on the driver's heterogeneous characteristics.

In addition, what needs to be elaborated is that exploring the sharing intention of parking space owners is also a critical area of study, since some problems with shared parking schemes, such as overtime, increased noise, and possible traffic congestion, need to be coordinated with parking space owners. However, this is out of the scope of this study, and readers are referred to the study proposed by Wang et al. [17-19], where they explored the influence of demographic attributes, built environment, and other factors of owners on their intention to participate in the shared parking schemes.

The rest of this paper is organized as follows: the next section extensively reviews literature concerning shared parking and research methods; in Section 3, the model framework, the multiple indicator multiple cause model and, the latent class modeling approach are briefly introduced; Section 4 profiles the dataset used in this study, including the survey outline, data collection, selected variables, and its descriptive analysis; in Section 5, the results and analysis are presented, including results of MIMIC and LCM estimation. At last, Section 6 concludes this research by summarizing implications and key findings, discussing limitations of the study, and presenting potential research topics.

\section{Literature Review}

2.1. Shared Parking. As far as we know, Lalani [20] proposed the concept of shared parking firstly, which also marks the transition from the nature of parking spaces to commodities. Shared parking has become an effective way to improve the utilization of existing parking resources. Litman [21] estimated that shared parking could reduce the need for new spaces by 10-30\%. Yan et al. [7] combined prospect theory and logit model to identify the intention of suppliers to participate in shared parking considering uncertain demands. Besides, the matching mechanism of shared parking spaces is an important part of the research related to shared parking. Shao et al. [22] firstly developed a parking space matching model between the supply and demand for residential parking spaces, Iman and Hamid [23] and Kim et al. [24] built matching models based on GIS and other technologies. Xiao et al. [25] proposed a dual auction mechanism for shared parking spaces considering multiple periods. In addition, Zhao et al. [26] developed an intelligent parking management system (IPMS) to simulate the operation of the shared parking system. In addition to the participation behavior and the matching of shared parking, there are also studies based on its pricing. Some scholars have constructed pricing strategies for parking charges based on marginal cost theory and suboptimal pricing theory $[27,28]$. Chen and Xie [29] established a dynamic allocation model of shared parking spaces for universities in the central city and conducted an effective evaluation. A competitive auction 
mechanism also was presented based on berth allocation rules and transaction payment rules [30].

2.2. Unified Theory of Acceptance and Use of Technology. Plentiful theoretical models have been developed in behavioral research to analyze and explain the public's acceptance of a certain technology, including rational behavior theory, technology acceptance model, motivation model, planned behavior theory, technology acceptance model, and planned behavior theory [31]. In the study of the acceptance of new technologies, the most widely used models are the technology acceptance model and the unified theory of acceptance and use of technology.

In 2003, Venkatesh et al. [32] proposed a unified model called "the unified theory of acceptance and use of technology." He pointed out that the eight models mentioned above only explained $17 \%-53 \%$ of the differences in users' intention to use information technology, while the unified theory of acceptance and use of technology model performed better than them. Similarly, Chen et al.'s [33] research also supports this conclusion. Four core variables, i.e., performance expectancy (PE), effort expectancy (EE), facilitating conditions (FCs), and social influence (SI), and exogenous variables such as age, gender, income, and education are proposed in the unified theory of acceptance and use of technology.

Some scholars have explored the public's acceptance of various road transportation systems based on the unified theory of acceptance and use of technology [34-38]. Although the unified theory of acceptance and use of technology has a forceful universality in practice, it cannot fully explain the actual behavior in some scenarios [33]; that is, except the above factors, behavioral intention may also be affected by some other hidden factors that have not been discovered. To better explain the intention and behavior, some new variables have been incorporated in plentiful existing studies according to the characteristics of the research object.

2.3. Latent Class Model (LCM). In recent years, LCM has been applied to traffic segmentation. Teichert et al. [39] recognized the limitations of traditional segmentation techniques, adopted LCM to classify air passengers, and explored the importance of routes and flight segments to airlines' selection behavior; Crouch et al. [40] collected data on people's past vacation experience choices, travel motives, and basic demographic characteristics, established LCM to divide tourists into 5 classes, and explored how tourists choose vacation experiences/activity types. Xiong et al. [41] used the LCM to reveal the significant heterogeneity of Maryland drivers' potential preferences for carpooling, which supports traffic policies and incentive mechanisms related to congestion management strategies (such as HOV/ HOT channel use). In addition, LCM is also widely used in other studies, such as long-distance drivers' route selection behavior [42], bicycle users [43], driving behavior on combined road segments [44], the time spent by tourists at destinations [45], the acceptance of self-driving vehicles [15], and the satisfaction with public transportation [13]. All of these studies have proved the advantages of potential category model segmentation research. Traveler segmentation studies that consider psychological factors have higher predictive power than individual attribute segmentation studies $[46,47]$.

2.4. Summary. Although the related research studies are fruitful, to the best of our knowledge, no previous study has explored the impact of drivers' heterogeneity on the SPUI. In addition, in the above studies on LCM, the explicit variables that determine the classification results are often entered into the LCM estimation without analysis, which will inevitably affect the accuracy of model estimation [48]. Therefore, this study innovatively uses MIMIC's output results as input variables of LCM to analyze the taste heterogeneity of different classes of drivers more accurately. This approach is expected to contribute to the literature by providing first-hand insights into SPUI of different categories of drivers.

\section{Methods}

3.1. Model Framework. In order to analyze the influence of psychological factors, personal attributes, and travel characteristics on SPUI, a MIMIC model is constructed to explore the causal relationship between various factors and SPUI. After that, based on the results of the MIMIC model, in order to identify the heterogeneity of preference among different categories of drivers, this study constructs LCM to explore potential driver classes and analyzes the characteristics of different classes. The model framework is shown in Figure 1.

Shared parking provides drivers with more parking options, but it also brings them safety and other concerns; therefore, the SPUI may be influenced by the perceived risks [18]. Besides, Xu [49] pointed out that when travelers have accumulated certain travel experiences in intercity travel choices, travelers tend to form the inertia of adopting a specific behavior under specific selection conditions, and such inertial behavior will enhance the effect of behavior habit $(\mathrm{BH})$ on usage intention (UI). So, we assume that $\mathrm{BH}$ will also affect SPUI; therefore, we construct the extended unified theory of the acceptance and use of technology model by incorporating $\mathrm{PR}$ and $\mathrm{BH}$ variables into the original unified theory of acceptance and use of technology to identify the factors influencing SPUI. The structural equation between the psychological factors can reflect the internal influence relationship between the psychological factors, and the structural equation between the exogenous variables and the psychological factors can reflect the degree of influence of the exogenous variables on the psychological factors [50].

Based on the analysis of the relationship between the influencing factors and SPUI, the difference between the driver's choice intention and preference is further explored. LCM is used to subdivide the driver category, as shown in the LCM framework in Figure 1. In traveler segmentation 


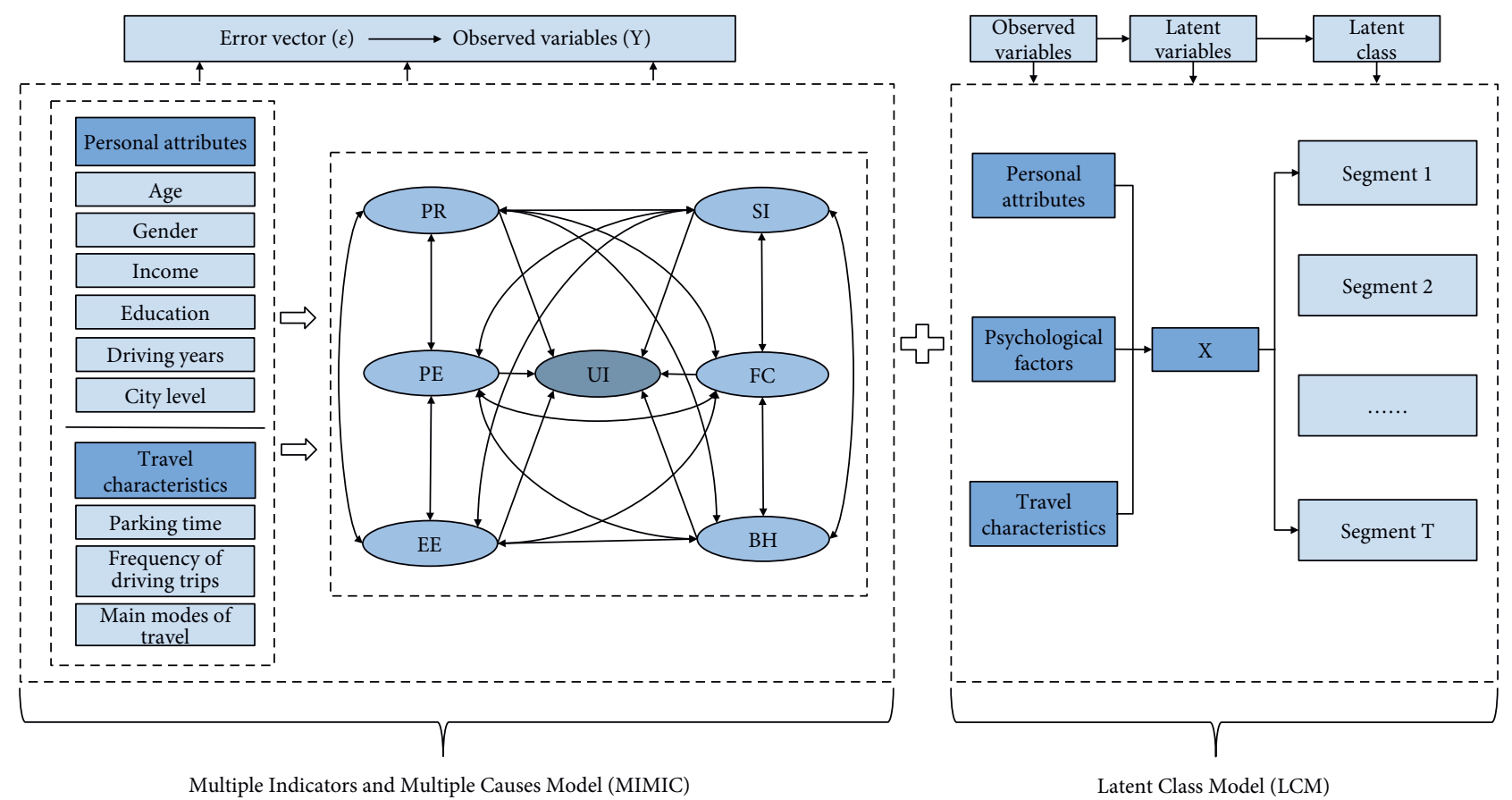

FIgURE 1: Modeling framework.

studies, demographic factors are usually regarded as basic classification indicators, such as age, gender, occupation, and income [51]. In addition, tourism-related factors [11] and various factor combinations [39] are also used for segmentation research. The driver's choice behavior is closely related to travel characteristics, such as driving frequency and parking time. Therefore, this article comprehensively considers the combination of personal attributes, travel characteristics, and psychological factors for subdivided research. The solution result of the MIMIC model is the influence relationship of various factors on SPUI. Variables that have a significant influence on SPUI are taken as input variables of LCM to obtain the number of types of driver groups and the specific characteristics of each type, such as the distribution and comparison of input variables. Finally, the characteristics of each category are summarized and analyzed.

\subsection{Multiple Indicator and Multiple Causes (MIMIC) Model.} Compared with the traditional SEM model and other models, the MIMIC model can not only express the exogenous causes and endogenous indicators of latent variables clearly through a strict structural model but also obtain the influence degree of all explanatory variables on latent variables, and this analysis method can make normal statistical relationship test more convenient [52]. Schneider and Enste [53] proposed that the MIMIC model can deal with multiple latent variables and endogenous indicators without strict constraints and assumptions, and allow exogenous causes and endogenous indicators to contain measurement errors. Therefore, its theoretical framework is more flexible than other indirect measurement methods, potentially including all other indirect measurement methods.
Therefore, this study intends to use the MIMIC model to explore the influence of psychological factors and exogenous variables on the SPUI.

The matrix form of MIMIC is shown in the equations as follows:

$$
\begin{aligned}
& \eta=\Gamma x+\zeta . \\
& y=\Lambda \eta+\varepsilon
\end{aligned}
$$

where $\eta$ is the psychological factor vector; $x$ indicates the exogenous variable vector; $y$ is the observation variable vector; $\Gamma$ and $\Lambda$ are the parameter matrixes to be estimated; $\zeta$ and $\varepsilon$ represent the measurement errors.

We substitute equation (1) into equation (2) to obtain

$$
\begin{aligned}
y=\Lambda(\Gamma x+\zeta)+\varepsilon & =\Pi x+v, \\
\Pi & =\Lambda \Gamma x, \\
v & =\Lambda \zeta+\varepsilon .
\end{aligned}
$$

Assuming that the measurement errors are independent of each other and subject to normal distribution, then $E\left(\zeta \varepsilon^{\prime}\right)=0, E\left(\zeta^{2}\right)=\delta^{2}, E(\zeta \varepsilon \varepsilon)=\Theta^{2} . \Theta^{2}$ is the lower triangular matrix of $v$, so the covariance matrix formula is

$$
\begin{aligned}
\sum(\theta) & =E\left(v v^{\prime}\right) \\
& =\delta^{2} \Lambda \Lambda^{\prime}+\Theta^{2} .
\end{aligned}
$$

The total covariance matrix can be calculated by observing the sample values of the variables, so $\sum=\sum(\theta)$; each parameter can be solved.

In the multiindex part of the MIMIC model, it is equivalent to the confirmatory factor analysis of psychological factors. The multicause part can be expressed as 


$$
\begin{aligned}
\eta_{l i}= & \gamma_{l 1} X_{\text {gender }_{i}}+\gamma_{l 2} X_{\text {age }_{i}}+\gamma_{l 3} X_{\text {inc }_{i}} \\
& +\gamma_{l 4} X_{\text {edu }_{i}}+\gamma_{l 5} X_{\text {year }_{i}}+\gamma_{l 6} X_{\text {city }_{i}} \\
& +\gamma_{l 7} X_{\text {awareness }_{i}}+\gamma_{l 8} X_{\text {time }_{i}}+\gamma_{l 9} X_{\text {frequency }_{i}}
\end{aligned}
$$

where $l$ is the psychological factor, including EE, SI, FC, PE, $\mathrm{PR}, \mathrm{BH}$, and UI; $\gamma$ indicates the parameter to be estimated; $i$ represents the observed individual.

3.3. Latent Class Model (LCM). LCM is a modeling analysis technique to explore latent variables, which is not only a statistical method but also a statistical methodology [54]. The most important feature of the latent category model is that it can process classification data and use the maximum likelihood method to estimate parameters, which can calculate the appropriate number of categories more accurately. In addition, the classification results are relatively stable and can be generalized in other samples of the same population, which is convenient for practical application $[55,56]$. It is an important research method to subdivide travelers' travel behavior differences with distinctive characteristics by using the potential category model [57]. It can overcome the shortcoming of traditional cluster analysis that deterministically assign travelers to a single group while ignoring the possibility of misclassification to the wrong group [58], such as $\mathrm{K}$-means++ and DBSCAN. The LCM analysis process consists of three steps: probability parameterization, model fitting and parameter estimation, and latent classification and result interpretation [59].

(1) Probability parameterization. It is the first step that converts the probability of classifying variables into a parameter model [11]. In this paper, personal attributes, psychological factors, and travel characteristics are taken as three explicit variables $\mathrm{A}, \mathrm{B}$, and $\mathrm{C}$, whose conditional probabilities are referred to $\pi_{i t}^{\bar{A} x}, \pi_{j t}^{\bar{B} x}$, and $\pi_{k t}^{\bar{C} x}$. The sum of conditional probability of all observed variables at each level is 1 , and the formula is as follows:

$$
\sum_{i} \pi_{i t}^{\bar{A} X}=\sum_{j} \pi_{j t}^{\bar{B} X}=\sum_{k} \pi_{k t}^{\bar{C} X}=1 .
$$

Assuming that there is a latent variable $X$ with $t$ $(t=1,2,3, \ldots, \mathrm{T})$ latent categories can explain the relationship between the three latent variables $\mathrm{A}, \mathrm{B}$, and $\mathrm{C}$, the LCM can be expressed as follows [60]:

$$
\pi_{i j k}^{A B C}=\sum_{t=1}^{T}\left(\pi_{t}^{X} \times \pi_{i t}^{\bar{A} X} \times \pi_{j t}^{\bar{B} X} \times \pi_{k t}^{\bar{C} X}\right) .
$$

(2) Model fitting and parameter estimation. Maximum Likelihood (ML) is mainly used for parameter estimation in potential category models, and the commonly used iterative algorithms include Expectation Maximization (EM), and Newton Rapson (NR). In this paper, the expectation maximization algorithm is used for iterative analysis. The ML estimation function is as follows:

$$
\pi_{i j k t}^{A B C X}=\pi_{t}^{X} \times \pi_{i t}^{\bar{A} X} \times \pi_{j t}^{\bar{B} X} \times \pi_{k t}^{\bar{C} X} .
$$

(3) Latent classification and result interpretation. By diving $\pi_{i j k t}^{A B C X}$ and $\pi_{i j k}^{A B C}$, the ML probability of observed variables in different potential categories at each level can be obtained, and the formula is as follows:

$$
\pi_{i j k t}^{A B C \bar{X}}=\frac{\pi_{i j k t}^{A B C X}}{\pi_{i j k}^{A B C}} .
$$

The posterior probability of each sample belonging to different latent classes is calculated, and the one with the highest value is the class to which the observed value belongs. The formula is as follows:

$$
\pi_{t i j k}^{\bar{X} A B C}=\frac{\pi_{i j k t}^{A B C X}}{\sum_{t=1}^{T} \pi_{i j k t}^{A B C X}} .
$$

\section{Data}

4.1. Sample. To ensure the data quality of the questionnaire, we conducted a presurvey in which we asked people with different levels of knowledge about shared parking to fill in the questionnaire and adjusted the questionnaire according to the presurvey results.

The final questionnaire consists of three parts: the first part is the information about parking on the latest trip; the second part is scene simulation; the third part covers the measurement items of the extended unified theory of acceptance and use of technology model variables, including EE, SI, FC, PR, PE, BH, and UI; the fourth part includes the respondents' socioeconomic attributes, parking characteristics, and travel characteristics. This study chiefly used the third and fourth parts of the questionnaire.

This study uses the Likert five-level scale - from "Strongly Disagree (=1)" to "Strongly Agree (=5)" to measure all psychological factors. It is used to rank respondents' recognition of the relevant descriptions given in each questionnaire measurement item for reflecting drivers' psychological feelings about shared parking. The measurement items constituting the questionnaire were adapted from scales validated in previous literature studies and modified by experts to reflect the specific environment and target population of shared parking. The six psychological factors of the theoretical model contain a total of 31 measurement items. Table 1 presents items related to psychological factors.

We carried out the formal survey using an online questionnaire in February 2021. There is no limit to the location distribution of respondents, and individuals with links to the survey and interest in the study are invited to participate. Individuals were considered eligible for inclusion if they met the following criteria: they were Chinese, had a valid driver's license, and had recently parked in an urban area for longer than 30 minutes. After conditional screening, the number of valid questionnaires in this study is 
TABLE 1: Construction and measurement items of psychological factors.

\begin{tabular}{|c|c|c|c|}
\hline Psychological factor & Project & Measurement item & Source \\
\hline $\begin{array}{l}\text { Facilitating Conditions } \\
\text { (FCs) }\end{array}$ & $\begin{array}{l}\text { FC3 } \\
\text { FC4 } \\
\text { FC5 } \\
\text { FC6 }\end{array}$ & $\begin{array}{c}\text { If the operation of shared parking app is easy to understand, I prefer to choose shared parking } \\
\text { space in residential areas } \\
\text { If the transaction of shared parking app is safe and convenient, I prefer to choose shared } \\
\text { parking space in residential areas } \\
\text { If relevant institutions establish shared parking credit mechanism, I prefer to use shared } \\
\text { parking space in residential areas } \\
\text { Shared parking will certainly get policy support } \\
\text { Existing technology is sufficient to support the normal operation of shared parking } \\
\text { I am willing to increase the walking distance to pay less parking fees }\end{array}$ & {$[18,61]$} \\
\hline Social Influence (SI) & SI2 & $\begin{array}{l}\text { If all my friends and relatives are using the shared parking space in the residential area, I will } \\
\text { also use it } \\
\text { The encouragement from relatives and friends around me will make me more willing to } \\
\text { choose the shared parking space in the residential area } \\
\text { The encouragement and appeal from the government and media will make me more willing to } \\
\text { choose shared parking spaces in residential areas } \\
\text { Choosing to use a shared parking space in a residential area makes me feel technologically } \\
\text { advanced }\end{array}$ & {$[61,62]$} \\
\hline Effort Expectancy (EE) & $\begin{array}{l}\text { EE1 } \\
\text { EE2 } \\
\text { EE3 } \\
\text { EE4 }\end{array}$ & $\begin{array}{c}\text { Shared parking spaces in residential areas are easy to find } \\
\text { I can quickly get used to the shared parking system in my residential area } \\
\text { The shared parking system would be simple to use } \\
\text { I feel completely in control of using the residential parking share system }\end{array}$ & [32]] \\
\hline Perceived Risk (PR) & $\begin{array}{l}\text { PR1 } \\
\text { PR2 }\end{array}$ & $\begin{array}{c}\text { It is difficult to find the reserved shared parking space in the residential area } \\
\text { Choosing to use shared parking spaces in residential areas has a high risk of exposing personal } \\
\text { privacy (such as vehicle information and location information) } \\
\text { If you park over time (beyond the scheduled time), it will cause more inconvenience for others } \\
\text { to use the parking space } \\
\text { At present, the related equipment and policy mechanism of shared parking are not perfect } \\
\text { enough } \\
\text { Parking in a shared parking space in a residential area increases vehicle safety risks }\end{array}$ & {$[18,63]$} \\
\hline $\begin{array}{l}\text { Performance } \\
\text { Expectancy (PE) }\end{array}$ & $\begin{array}{l}\text { PE3 } \\
\text { PE4 } \\
\text { PE5 }\end{array}$ & $\begin{array}{l}\text { Using a shared parking space in a residential area will reduce my parking expenses } \\
\text { Using shared parking spaces in residential areas can reduce the time spent looking for a } \\
\text { parking space } \\
\text { Using shared parking spaces in residential areas can improve the efficiency and quality of my } \\
\text { study, work, and life } \\
\text { Shared parking is good for the sustainable development of the city } \\
\text { Shared parking can alleviate the problem of "hard parking" }\end{array}$ & [64-66] \\
\hline Behavior Habit (BH) & $\begin{array}{l}\mathrm{BH} 1 \\
\mathrm{BH} 2 \\
\mathrm{BH} 3\end{array}$ & $\begin{array}{l}\text { Next time when I park my car, I will continue to use the public parking lot } \\
\text { Public parking is my usual choice } \\
\text { I usually do not actively consider choosing new parking options (such as shared parking) }\end{array}$ & [49] \\
\hline Usage Intention (UI) & $\begin{array}{l}\text { UI1 } \\
\text { UI2 } \\
\text { UI3 } \\
\text { UI4 }\end{array}$ & $\begin{array}{l}\text { I would like to try to use shared parking space in residential areas in the future } \\
\text { I would like to give priority to using shared parking spaces in residential areas in the future } \\
\text { I will often use the shared parking space in the residential area } \\
\text { I will strongly recommend my relatives and friends to use shared parking spaces in residential } \\
\text { areas in the future }\end{array}$ & {$[33,38]$} \\
\hline
\end{tabular}

217. The sample size should be at least 5-10 times the variable in multivariate research using structural equation [50], which means the sample size of formal investigation should be more than 155 , so the sample size of formal investigation can meet the research needs.

In an effective sample, the drivers surveyed were evenly distributed in cities of different levels, accounting for about $20 \%$ in first-tier, second-tier, and third-tier cities, and 35\% in fourth-tier cities. The number of male drivers $(63.13 \%)$ was higher than that of female drivers (36.87\%). The respondents were mainly aged from 18 to 30 years old (61.29\%), which accords with the age distribution structure of Chinese drivers, and those older than 30 years old were evenly distributed. $42.86 \%$ of the respondents had a college or bachelor's degree, and more than 30\% had a master's degree or above. More than half of the respondents earned less than 5,000 yuan, which is consistent with the income characteristics of Chinese residents. Table 2 summarizes the main demographic characteristics of the valid sample.

\subsection{Data Analysis}

4.2.1. Measurement Model Testing. Firstly, exploratory factor analysis was carried out using SPSS, and KMO and Bartlett's sphere tests were performed on the scale. The 
TABLe 2: Demographic characteristics of the participants.

\begin{tabular}{|c|c|c|c|}
\hline Characteristics & Item & Proportion (\%) & Variable naming \\
\hline \multirow{2}{*}{ Gender } & Male & 63.13 & \multirow{2}{*}{ Gender } \\
\hline & Female & 36.87 & \\
\hline \multirow{6}{*}{ Age } & $18-25$ & 40.09 & \multirow{6}{*}{ Old } \\
\hline & $26-30$ & 21.2 & \\
\hline & $31-40$ & 14.75 & \\
\hline & $41-50$ & 11.06 & \\
\hline & $51-60$ & 9.68 & \\
\hline & $>60$ & 0.46 & \\
\hline \multirow{3}{*}{ Driving experiences } & $\leq 1$ & 33.64 & \multirow{3}{*}{ Year } \\
\hline & $1-3$ & 26.73 & \\
\hline & $\geq 3$ & 39.63 & \\
\hline \multirow{4}{*}{ Education level } & High school or below & 25.81 & \multirow{4}{*}{ Education } \\
\hline & College/undergraduate & 42.86 & \\
\hline & Master & 26.73 & \\
\hline & Doctor & 4.61 & \\
\hline \multirow{6}{*}{ Monthly income } & $<3000$ yuan & 31.34 & \multirow{6}{*}{ Income } \\
\hline & $3000-5000$ yuan & 23.04 & \\
\hline & $5000-7000$ yuan & 18.43 & \\
\hline & $7000-9000$ yuan & 11.52 & \\
\hline & $9000-11000$ yuan & 3.69 & \\
\hline & $>11000$ yuan & 11.98 & \\
\hline \multirow{4}{*}{ City level } & First-tier city & 22.58 & \multirow{4}{*}{ City } \\
\hline & Second-tier city & 22.58 & \\
\hline & Third-tier city & 19.82 & \\
\hline & Fourth-tier city & 35.02 & \\
\hline \multirow{5}{*}{ Understanding degree of shared parking } & Do not understand at all & 7.83 & \multirow{5}{*}{ Awareness } \\
\hline & Do not understand & 24.42 & \\
\hline & General understanding & 52.53 & \\
\hline & Better understand & 11.98 & \\
\hline & Understand very well & 3.23 & \\
\hline \multirow{4}{*}{ Average daytime parking time on weekdays } & $<2 \mathrm{~h}$ & 22.12 & \multirow{4}{*}{ Time } \\
\hline & $2-5 \mathrm{~h}$ & 23.5 & \\
\hline & $5-8 \mathrm{~h}$ & 30.41 & \\
\hline & $>8 \mathrm{~h}$ & 23.96 & \\
\hline \multirow{4}{*}{ Driving frequency } & 1-4 times per week & 58.53 & \multirow{4}{*}{ Frequency } \\
\hline & 5-8 times per week & 23.96 & \\
\hline & $9-12$ times per week & 9.68 & \\
\hline & $>12$ times per week & 7.83 & \\
\hline
\end{tabular}

results showed that the KMO value was $0.902(>0.700)$, and Bartlett's sphericity test value was significant (sig.<0.001), indicating that the questionnaire data met the prerequisite requirements of factor analysis.

Cronbach's $\alpha$, composite reliability, and average variance extracted were used to evaluate the reliability and validity of the questionnaire. Table 3 shows the reliability and validity of test results. If Cronbach's $\alpha$ is higher than 0.8 , the reliability is high; if it is between 0.7 and 0.8 , the reliability is acceptable; if it is between 0.6 and 0.7 , it is basically acceptable; if it is less than 0.6 , the reliability is not good, and the survey scale should be revised [67]. Based on analysis results, only Cronbach's $\alpha$ of $\mathrm{BH}$ is 0.784 , and Cronbach's $\alpha$ of other psychological factors are all higher than 0.8 , indicating that the reliability of the questionnaire is very high.

When the average variance extracted (AVE) value is greater than 0.5 , it indicates that the psychological factor has good convergence validity [68]. In addition, when the outer loading coefficient corresponding to each observation variable is greater than 0.6 and $P<0.05$, it also indicates that the convergence validity is up to standard. Just as the results in Table 4, the minimum AVE value of the psychological factor is 0.567 , and the outer loading coefficient of each measurement item is above 0.66 , indicating that the data have strong reliability and internal consistency.

4.2.2. Structural Model Testing. The chi-square degree of freedom ratio $\left(\chi^{2} / \mathrm{d} f\right)$, Root Mean Squared Error of Approximation (RMSEA), Goodness-of-Fit Index (GFI), Comparative Fit Index (CFI), and Adjust Goodness-ofFit Index (AGFI) were selected as evaluation indexes of model fit degree. The MIMIC model was employed for parameter estimation and model assessment to characterize the intentions of drivers toward the use of parking 
TABLE 3: Measurement items for all the relevant constructions.

\begin{tabular}{|c|c|c|c|c|c|c|}
\hline Latent variable & Item no. & Outer loading & Mean & SD & $\alpha$ & AVE \\
\hline \multirow{6}{*}{ Facilitating Conditions (FCs) } & $\mathrm{FC} 1$ & 0.918 & 3.83 & 0.793 & \multirow{6}{*}{0.921} & \multirow{6}{*}{0.683} \\
\hline & FC2 & 0.943 & 3.80 & 0.811 & & \\
\hline & FC3 & 0.916 & 3.82 & 0.787 & & \\
\hline & FC4 & 0.735 & 3.68 & 0.865 & & \\
\hline & FC5 & 0.741 & 3.47 & 0.901 & & \\
\hline & FC6 & 0.661 & 3.76 & 0.856 & & \\
\hline \multirow{4}{*}{ Social Influence (SI) } & SI1 & 0.923 & 3.65 & 0.826 & \multirow{4}{*}{0.928} & \multirow{4}{*}{0.765} \\
\hline & SI2 & 0.895 & 3.60 & 0.861 & & \\
\hline & SI3 & 0.900 & 3.73 & 0.808 & & \\
\hline & SI4 & 0.775 & 3.53 & 0.892 & & \\
\hline \multirow{4}{*}{ Effort Expectancy (EE) } & EE1 & 0.693 & 3.39 & 3.39 & \multirow{4}{*}{0.876} & \multirow{4}{*}{0.663} \\
\hline & EE2 & 0.854 & 3.56 & 0.873 & & \\
\hline & EE3 & 0.849 & 3.50 & 0.918 & & \\
\hline & EE4 & 0.849 & 3.39 & 0.886 & & \\
\hline \multirow{5}{*}{ Perceived Risk (PR) } & PR1 & 0.843 & 3.49 & 0.849 & \multirow{5}{*}{0.915} & \multirow{5}{*}{0.690} \\
\hline & PR2 & 0.748 & 3.40 & 0.904 & & \\
\hline & PR3 & 0.914 & 3.73 & 0.889 & & \\
\hline & PR4 & 0.856 & 3.71 & 0.842 & & \\
\hline & PR5 & 0.779 & 3.49 & 0.942 & & \\
\hline \multirow{5}{*}{ Performance Expectancy (PE) } & PE1 & 0.699 & 3.44 & 0.925 & \multirow{5}{*}{0.914} & \multirow{5}{*}{0.684} \\
\hline & PE2 & 0.824 & 3.60 & 0.797 & & \\
\hline & PE3 & 0.706 & 3.47 & 0.926 & & \\
\hline & PE4 & 0.954 & 3.79 & 0.779 & & \\
\hline & PE5 & 0.920 & 3.76 & 0.799 & & \\
\hline \multirow{3}{*}{ Behavior Habit (BH) } & $\mathrm{BH} 1$ & 0.763 & 3.62 & 0.822 & \multirow{3}{*}{0.784} & \multirow{3}{*}{0.567} \\
\hline & $\mathrm{BH} 2$ & 0.776 & 3.77 & 0.775 & & \\
\hline & $\mathrm{BH} 3$ & 0.718 & 3.42 & 0.881 & & \\
\hline \multirow{4}{*}{ Usage Intention (UI) } & UI1 & 0.866 & 3.71 & 0.774 & \multirow{4}{*}{0.940} & \multirow{4}{*}{0.815} \\
\hline & UI2 & 0.922 & 3.45 & 0.793 & & \\
\hline & UI3 & 0.938 & 3.43 & 0.800 & & \\
\hline & UI4 & 0.885 & 3.39 & 0.815 & & \\
\hline
\end{tabular}

TABLE 4: Test results of goodness of fit.

\begin{tabular}{lccccc}
\hline Index & $\chi^{2} / \mathrm{d} f$ & RMSEA & GFI & CFI & AGFI \\
\hline Actual value & 1.537 & 0.064 & 0.801 & 0.950 & 0.737 \\
Standard value & $<3$ & $<0.3$ & $>0.8$ & $>0.9$ & $>0.8$ \\
\hline
\end{tabular}

space sharing systems based on AMOS software. Then, we found that the theoretical model and empirical data cannot be entirely fitting. Under the premise of not affecting the completeness of the theoretical model, the model was revised, and the path that had no significant impact was deleted. The calculation results of the test index of the final model fit are shown in Table 4. Except that the AGFI is slightly less than the standard value, other models are proposed. All the compliance indicators meet the requirements.

\section{Result Analysis}

5.1. Analysis of MIMIC Estimation Results. From the calibration results of the MIMIC model, we can see the relationship between personal attributes, travel characteristics and psychological factors, as well as the influence relationship between the psychological factors.
5.1.1. Analysis of the Influence Relationship between Psychological factors. The path relationship between the psychological factors in the shared parking use intention model is shown in Figure 2. The values on the path in the figure are standardized coefficients. In the figure, ${ }^{*}$ means $P<0.05,{ }^{* *}$ means $P<0.01$, and ${ }^{* * *}$ means $P<0.001$.

The impact of each psychological factor on UI is ranked from the highest to lowest as follows: FC $(\beta=0.677, \quad t$-value $=4.025, \quad P<0.001), \quad$ SI $\quad(\beta=0.452$, $t$ value $=1.958, P<0.05), \operatorname{EE}(\beta=0.443, t$ value $=3.306$, $P<0.001), \mathrm{BH}(\beta=0.229, t$ value $=2.052, P<0.05), \mathrm{PR}$ $(\beta=-0.214, \quad t$ value $=-0.232, \quad P<0.05), \quad$ except $\quad \mathrm{PE}$ $(\beta=0.170, t$ value $=1.100, P=0.271>0.05)$, other psychological factors all have a significant impact on UI, with a confidence interval of $95 \%$ (corresponding to $P<0.05$ ), the proportion of variance in UI that can be explained by FC, SI, EE, PR, BH is 59.6\% $\left(R^{2}=0.596\right)$. Marcoulides [69] pointed out the following evaluation criteria: $R^{2}$ lower 
than 0.19 indicates unacceptable explanatory power; 0.19-0.33 indicates weak explanatory power; $0.33-0.67$ indicates moderate explanatory power; higher than 0.67 indicates good explanatory power. Besides, the evaluation standard proposed by Cohen et al. [70] pointed out that when $R^{2}$ is greater than 0.4 , the model is considered to have good explanatory power. According to the evaluation criteria proposed by Marcoulides and Cohen, in addition, the results of Chen's [33] study $\left(R^{2}=0.48\right)$ also illustrate the validity of our result. So, it can be inferred that the theoretical model we constructed has a good explanatory power for the use intention of shared parking.

\subsubsection{Analysis of the Influence Relationship of Exogenous} Variables on Psychological factors. A summary of the impact of exogenous factors including population socioeconomic attributes, parking characteristics, and travel characteristics on FC, SI, PE, BH, EE, and PR is shown in Table 5.

Exogenous factors do not directly affect UI but indirectly affect UI by affecting FC, SI, PE, BH, EE, and PR. It can be seen from Table 5 that those exogenous variables do not have a significant impact on every psychological factor. Gender and the city level have no significant impact on all psychological factors, indicating that gender and the city level of the respondent do not affect their SPUI.

Age has a significant positive effect on $\mathrm{EE}(P<0.05)$, indicating that within a certain range, older people have to work harder to accept and adapt to the shared parking system. On the contrary, young people have strong confidence in the control of new things, which may be related to the limited network information and physiological factors accepted by the elderly, while modern young people receive more extensive information from the outside world and have more active thinking. Driving experiences have a significant positive impact on $\mathrm{PR}(P<0.05)$, indicating that the older the driving experiences, the more sensitive they are to the potential risks of shared parking; income has a significant negative impact on both FC $(P<0.01)$ and SI $(P<0.05)$; this shows that the higher the income, the less sensitive the attitudes of the external conditions and the surrounding people will be and will not be easily influenced by the outside world, this may be because people with higher incomes will look at new things more rationally; parking time has a significant positive effect on PE $(P<0.001)$, FC $(P<0.001)$, $\mathrm{BH}(P<0.05)$, SI $(P<0.01)$, and EE $(P<0.01)$; driving frequency has a significant negative impact on $\mathrm{PR}(P<0.05)$, $\mathrm{PE}(P<0.05)$, FC $(P<0.05)$, and SI $(P<0.05)$, indicating that the higher frequency of driving.

5.2. Analysis of LCM Segmentation Results. In this study, based on the results of the MIMIC model, 11 factors were selected initially to subdivide the driver category. These factors are age, income, driving experiences, education level, parking time, frequency of driving, the degree of confidence in the control of shared parking systems (EE4), the influence of walking distance (PC6), the influence of government and news media (SI3), the attractiveness of preferential fees (PE1), and the influence of parking choice habit (BH3). After calculation, the $P$ value of BH in LCM is greater than 0.05 , so the null hypothesis cannot be rejected. This variable cannot be effectively explained by the potential category, so $\mathrm{BH}$ is excluded from the explicit variables.

Because the number of classes $\mathrm{C}$ is initially unknown, we need to specify the value of $\mathrm{C}$ beforehand. According to literature [71], CAIC (Consistent Akaike Information Criterion) and BIC (Bayesian Information Criterion) indicators of LCM are used to determine category C. The smaller the CAIC and BIC values are, the higher the model fit degree is. Therefore, it is assumed that the samples can be divided into 1-10 classes. Then, LatentGOLD 5.0 software is used for LCM fitting and parameter estimation to obtain the CAIC and BIC values under a different number of classes. It can be seen from Figure 3 that when the number of classes is 4 , CAIC and BIC have the smallest values, so the sample can be divided into four classes.

Respondents are modeled based on potential category analysis, and model parameters are estimated. The results are shown in Table 6. From the results, the probabilities of the four potential classes are $0.3602,0.2964,0.2449$, and 0.0988 , respectively. Finally, the classification accuracy of the model is $\lambda=0.95$, which shows that the classification accuracy is high, and the classification results are reasonable [72].

The different observation factors of the latent class are analyzed, as shown in Figures 4-13. It is can be seen that the five observed psychological factors (EE4, SI3, FC6, and PE1) are also different in the latent classes, as shown in Figures 4-7, which shows their different psychological characteristics. There are significant differences among the observed factors age, driving experience, education level, income, parking time, and travel frequency in the latent classes, as shown in Figures 8-13.

According to the results of Figures 4-13 and Table 6, we characterized the segments as follows:

Segment 1 (36\% of the respondents) is mainly composed of people with relatively more positive psychological characteristics. This type of driver makes up the largest proportion. They are more likely to accept "long distance in exchange for less parking fees" than segments 2 and 3, and they are more optimistic about the potential economic benefits of shared parking, but they are more susceptible to the influence of the government and the media than segments 2 and 3, so we call them "sensitive type." The age and income distribution of the members of this class are relatively even. $61.1 \%$ of the respondents have more than three years of driving experience, more than $98 \%$ of the respondents have a bachelor's degree or above, and more than $40 \%$ of respondents parked for more than $8 \mathrm{~h}$ during working hours.

Segment 2 (29.6\% of the respondents) is mainly composed of people with relatively more conservative attitudes, which we call the "conservative type." Their degree of influence by the government and media is the least among the four segments, and their degree of confidence in the control of the shared parking system is basically the same as that of segment 3 but lower than that of segments 1 and 4; besides, they have no great expectation of reduced parking fees compared with other segments. The age distribution of this 


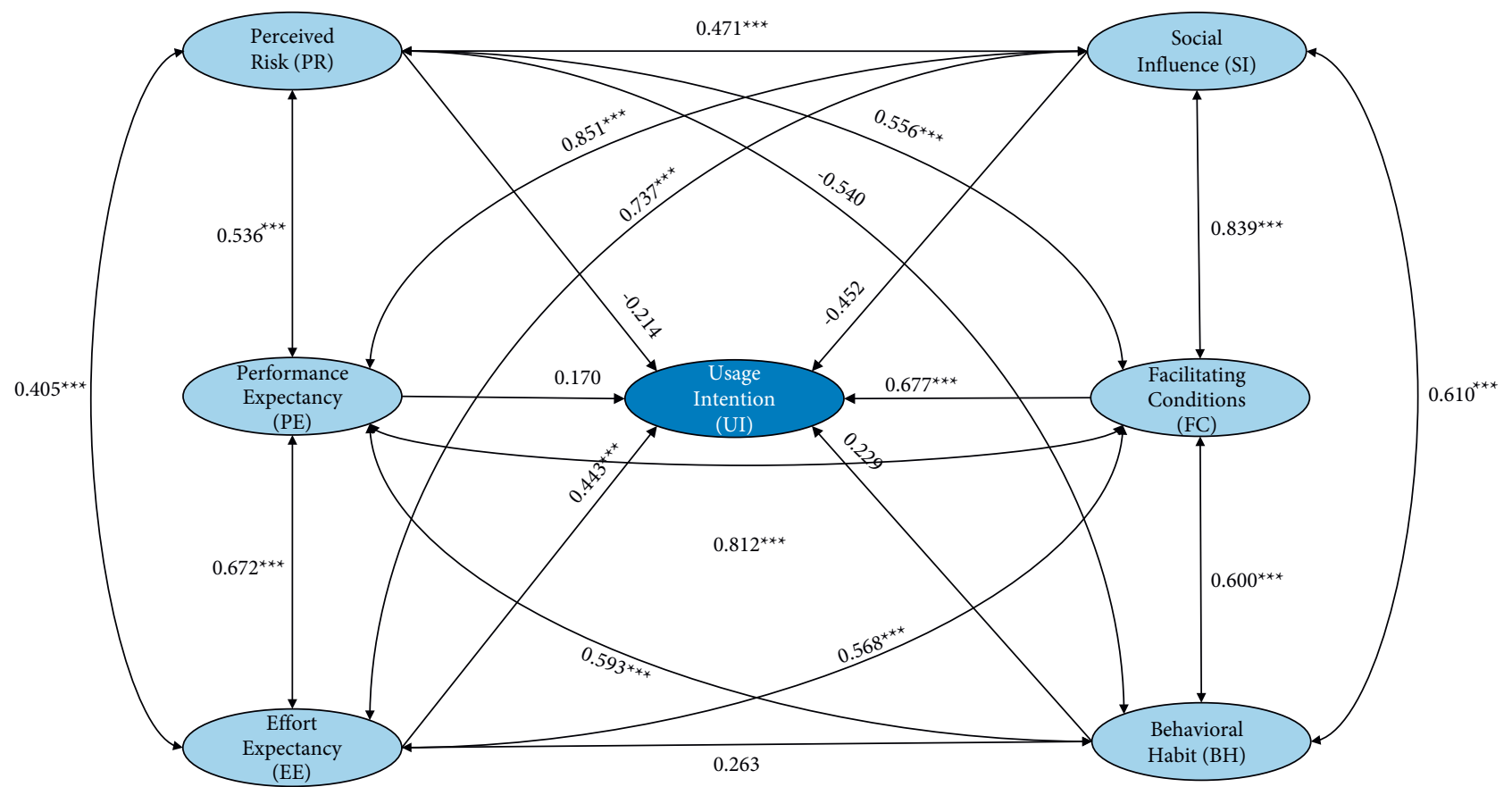

FIgURE 2: Analysis results of the structural model. Solid line indicates that there is a significant influence relationship; dashed line indicates that there is no significant influence relationship.

TABLE 5: Results of ANOVA.

\begin{tabular}{|c|c|c|c|c|c|c|c|c|}
\hline Variable & Frequency & Parking time & City level & Income & Education & Driving experiences & Age & Male \\
\hline PR & $-0.614^{*}$ & 0.395 & -0.133 & -0.247 & 0.067 & $0.494^{*}$ & -0.22 & 0.067 \\
\hline $\mathrm{PE}$ & $-0.287^{*}$ & $0.844^{* * *}$ & -0.069 & -0.048 & 0.221 & 0.000 & 0.131 & 0.148 \\
\hline FC & $-0.279^{*}$ & $0.734^{* * *}$ & -0.206 & $-0.384^{* *}$ & 0.222 & 0.037 & 0.212 & 0.155 \\
\hline $\mathrm{BH}$ & -0.376 & $0.539^{*}$ & -0.010 & -0.384 & 0.112 & 0.198 & 0.000 & 0.296 \\
\hline SI & $-0.462^{*}$ & $0.701^{* *}$ & -0.246 & $-0.358^{*}$ & 0.045 & 0.162 & 0.236 & 0.017 \\
\hline $\mathrm{EE}$ & -0.064 & $0.578^{* *}$ & -0.246 & 0.088 & $0.449^{*}$ & 0.156 & $0.540^{*}$ & 0.191 \\
\hline
\end{tabular}

Note. If the $P$ value is greater than 0.05 , the moderating effect is not significant; if the $P$ value is lower than 0.05 , the moderating effect is significant. ${ }^{* * *} P<0.001,{ }^{* *} P<0.01$, and ${ }^{*} P<0.05$.

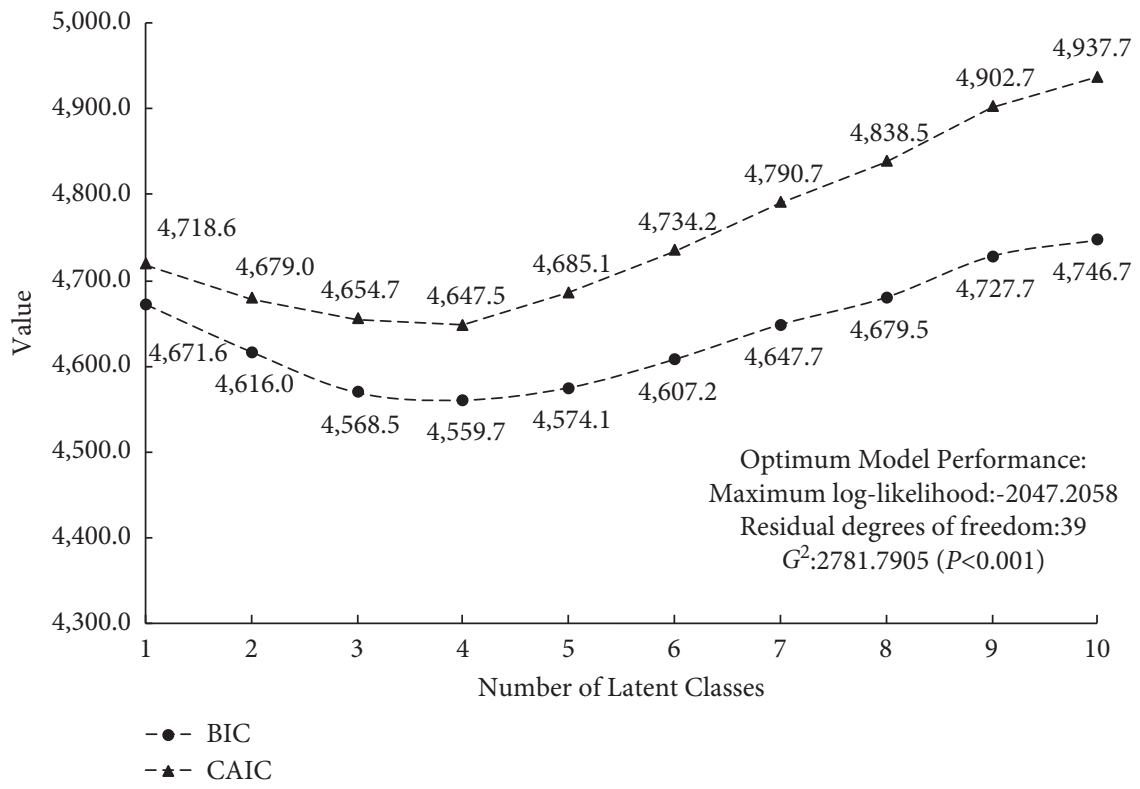

FIGURE 3: Optimum number of classes in the latent class model. 
TABle 6: Parameter estimation results of LCM (four latent classes: C1, C2, C3, and C4).

\begin{tabular}{|c|c|c|c|c|c|c|c|}
\hline \multirow{2}{*}{ Variable } & \multirow{2}{*}{ Observed Variable } & \multirow{2}{*}{ Level } & \multirow{2}{*}{ Description } & \multicolumn{4}{|c|}{ Conditional Probability of Latent Class } \\
\hline & & & & $\mathrm{C} 1$ & $\mathrm{C} 2$ & $\mathrm{C} 3$ & $\mathrm{C} 4$ \\
\hline \multirow{24}{*}{ Psychological factors } & \multirow{6}{*}{$\mathrm{EE} 4$} & 1 & Strongly disagree & 0.0178 & 0.0431 & 0.0436 & 0.0000 \\
\hline & & 2 & Disagree & 0.0716 & 0.1176 & 0.1182 & 0.0000 \\
\hline & & 3 & Generally agree & 0.4425 & 0.4913 & 0.4916 & 0.0013 \\
\hline & & 4 & Agree & 0.4538 & 0.3407 & 0.3395 & 0.1842 \\
\hline & & 5 & Strongly agree & 0.0144 & 0.0073 & 0.0072 & 0.8145 \\
\hline & & Mean & 3.3753 & 3.1514 & 3.1487 & 4.8132 & \\
\hline & \multirow{6}{*}{ SI3 } & 1 & Strongly disagree & 0.0071 & 0.0393 & 0.0334 & 0.0000 \\
\hline & & 2 & Disagree & 0.0080 & 0.0232 & 0.0210 & 0.0000 \\
\hline & & 3 & Generally agree & 0.2697 & 0.4055 & 0.3929 & 0.0000 \\
\hline & & 4 & Agree & 0.6377 & 0.5003 & 0.5176 & 0.0291 \\
\hline & & 5 & Strongly agree & 0.0775 & 0.0317 & 0.0350 & 0.9709 \\
\hline & & Mean & $3.7704^{\circ}$ & 3.4619 & 3.4999 & 4.9708 & \\
\hline & \multirow{6}{*}{ FC6 } & 1 & Strongly disagree & 0.0074 & 0.0436 & 0.0278 & 0.0000 \\
\hline & & 2 & Disagree & 0.0165 & 0.0495 & 0.0378 & 0.0000 \\
\hline & & 3 & Generally agree & 0.2713 & 0.4134 & 0.3792 & 0.0043 \\
\hline & & 4 & Agree & 0.5673 & 0.4393 & 0.4838 & 0.1746 \\
\hline & & 5 & Strongly agree & 0.1375 & 0.0541 & 0.0715 & 0.8211 \\
\hline & & Mean & 3.8110 & 3.4108 & 3.5335 & 4.8168 & \\
\hline & \multirow{6}{*}{ PE1 } & 1 & Strongly disagree & 0.0332 & 0.0758 & 0.0423 & 0.0000 \\
\hline & & 2 & Disagree & 0.0604 & 0.0959 & 0.0694 & 0.0000 \\
\hline & & 3 & Generally agree & 0.4032 & 0.4469 & 0.4189 & 0.0048 \\
\hline & & 4 & Agree & 0.4714 & 0.3643 & 0.4423 & 0.2479 \\
\hline & & 5 & Strongly agree & 0.0319 & 0.0172 & 0.0270 & 0.7474 \\
\hline & & Mean & 3.4083 & 3.1512 & 3.3423 & 4.7426 & \\
\hline \multirow{12}{*}{ Personal attributes } & \multirow{7}{*}{ Age } & 1 & $18-25$ & 0.0038 & 0.0001 & 0.0544 & 0.0020 \\
\hline & & 2 & $26-30$ & 0.2752 & 0.0300 & 0.7637 & 0.1862 \\
\hline & & 3 & $31-40$ & 0.2916 & 0.0883 & 0.1547 & 0.2528 \\
\hline & & 4 & $41-50$ & 0.2408 & 0.2024 & 0.0244 & 0.2675 \\
\hline & & 5 & $51-60$ & 0.1309 & 0.3056 & 0.0025 & 0.1864 \\
\hline & & 6 & $>60$ & 0.0576 & 0.3735 & 0.0002 & 0.1051 \\
\hline & & Mean & 3.3929 & 4.9038 & 2.1576 & 3.7654 & \\
\hline & \multirow{5}{*}{ Driving experience } & 1 & $\leq 1$ & 0.1490 & 0.2572 & 0.6764 & 0.1818 \\
\hline & & 2 & $1-3$ & 0.2403 & 0.2760 & 0.2155 & 0.2550 \\
\hline & & 3 & $\geq 3$ & 0.6107 & 0.4668 & 0.1081 & 0.5632 \\
\hline & & Mean & 2.4617 & 2.2096 & 1.4317 & 2.3813 & \\
\hline & & 1 & High school or below & 0.0166 & 0.7945 & 0.0178 & 0.5355 \\
\hline \multirow{11}{*}{ Personal attributes } & \multirow{4}{*}{ Education level } & 2 & College/Undergraduate & 0.4631 & 0.2038 & 0.4749 & 0.4517 \\
\hline & & 3 & Master & 0.4319 & 0.0017 & 0.4241 & 0.0127 \\
\hline & & 4 & Doctor & 0.0884 & 0.0000 & 0.0832 & 0.0001 \\
\hline & & Mean & 2.5922 & 1.2073 & 2.5727 & 1.4774 & \\
\hline & & 1 & $<3000$ yuan & 0.0769 & 0.3299 & 0.6277 & 0.2719 \\
\hline & & 2 & $3000-5000$ yuan & 0.1602 & 0.3281 & 0.2777 & 0.3124 \\
\hline & & 3 & $5000-7000$ yuan & 0.2118 & 0.2069 & 0.0779 & 0.2276 \\
\hline & Income & 4 & $7000-9000$ yuan & 0.1814 & 0.0846 & 0.0142 & 0.1074 \\
\hline & & 5 & $9000-11000$ yuan & 0.0968 & 0.0215 & 0.0016 & 0.0316 \\
\hline & & 6 & $>11000$ yuan & 0.2729 & 0.0289 & 0.0010 & 0.0491 \\
\hline & & & Mean & 3.8797 & 2.2265 & 1.4871 & 2.4617 \\
\hline & & 1 & $<2 \mathrm{~h}$ & 0.0752 & 0.2609 & 0.3218 & 0.1858 \\
\hline & & 2 & $2-5 \mathrm{~h}$ & 0.1258 & 0.2199 & 0.2324 & 0.1945 \\
\hline & Parking time & 3 & $5-8 \mathrm{~h}$ & 0.3764 & 0.3316 & 0.3003 & 0.3640 \\
\hline & & 4 & $>8 \mathrm{~h}$ & 0.4226 & 0.1876 & 0.1456 & 0.2557 \\
\hline Travel characterictics & & Mean & 3.1463 & 2.4460 & 2.2696 & 2.6896 & \\
\hline Iravel characteristics & & 1 & 1-4 times per week & 0.6159 & 0.3487 & 0.9920 & 0.5204 \\
\hline & & 2 & 5-8 times per week & 0.2888 & 0.3405 & 0.0080 & 0.3238 \\
\hline & Frequency of driving & 3 & $9-12$ times per week & 0.0665 & 0.1633 & 0.0000 & 0.0989 \\
\hline & & 4 & $>12$ times per week & 0.0288 & 0.1475 & 0.0000 & 0.0569 \\
\hline & & & Mean & 1.5082 & 2.1096 & 1.0080 & 1.6924 \\
\hline & Probability of late & class & & 0.3602 & 0.2961 & 0.2449 & 0.0988 \\
\hline
\end{tabular}




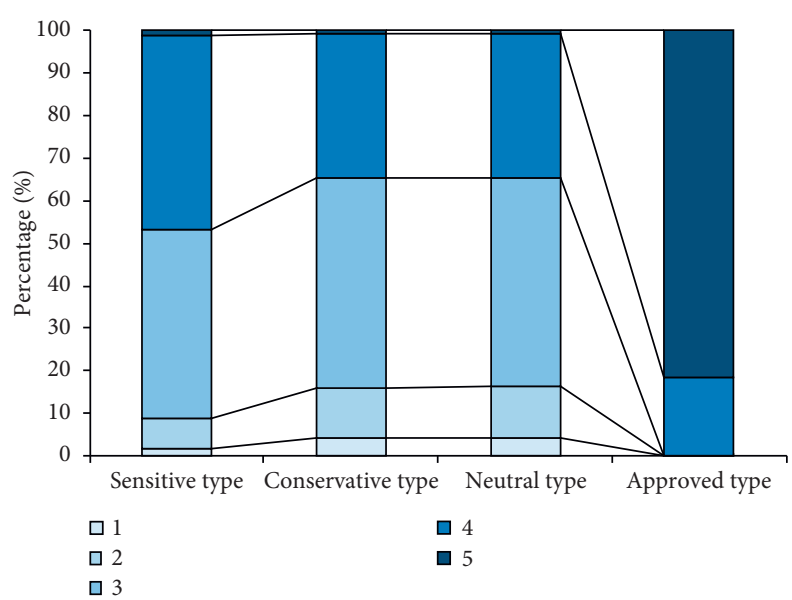

FIgURE 4: EE of drivers in the four segments.

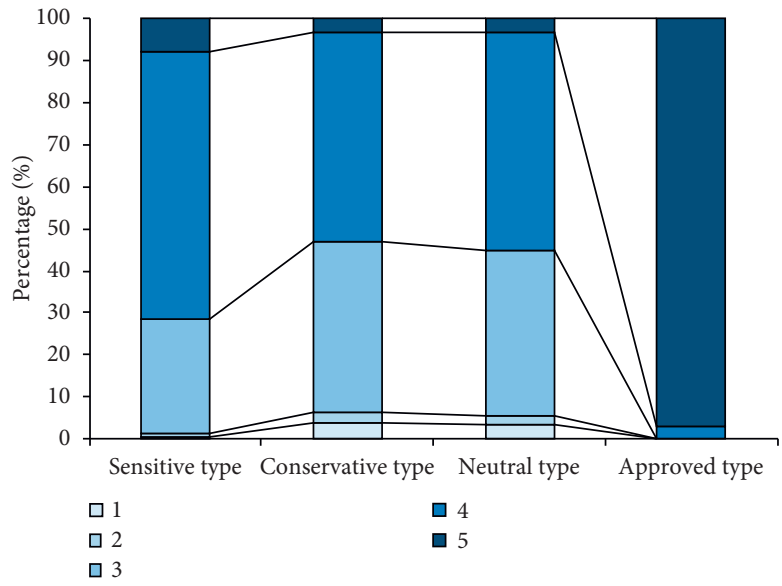

FIgURE 5: SI of drivers in the four segments.

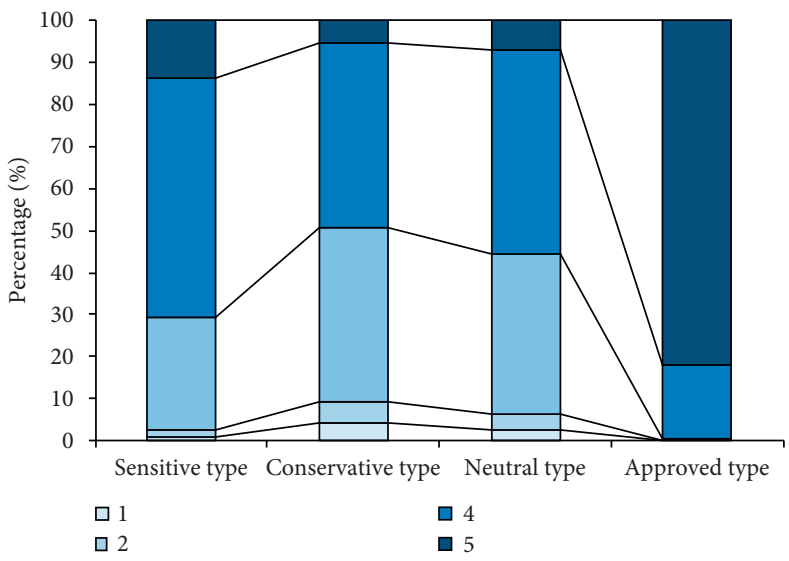

$\square 3$

Figure 6: FC of drivers in the four segments.

segment is relatively uniform, and the average education level is the lowest, while the average driving frequency is the highest; among the four segments, their monthly income is concentrated below 7000 yuan (86.5\%), but the parking time is lower than segments 1 and 4 . Therefore, it can be inferred that the randomness of their trips may be strong.

Segment 3 (24.5\% of the respondents) has the least confidence in the control of new things, and their response 


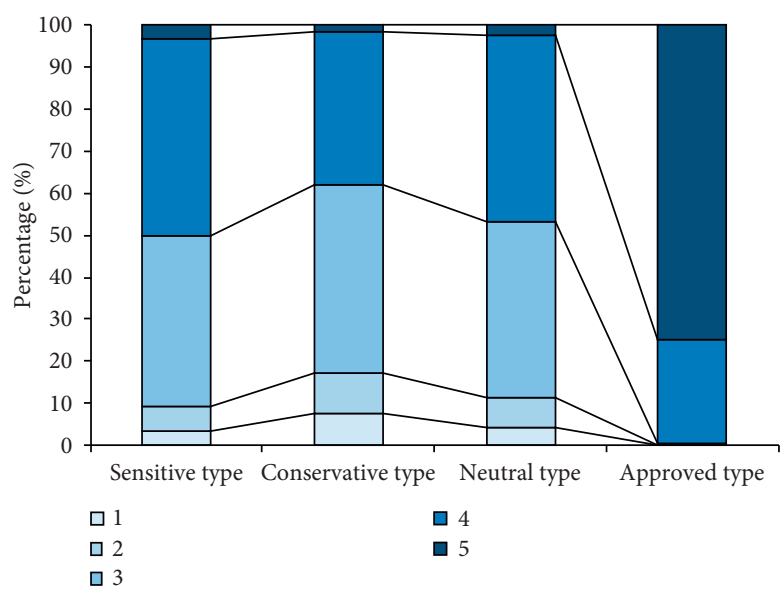

FIGURE 7: PE of drivers in the four segments.

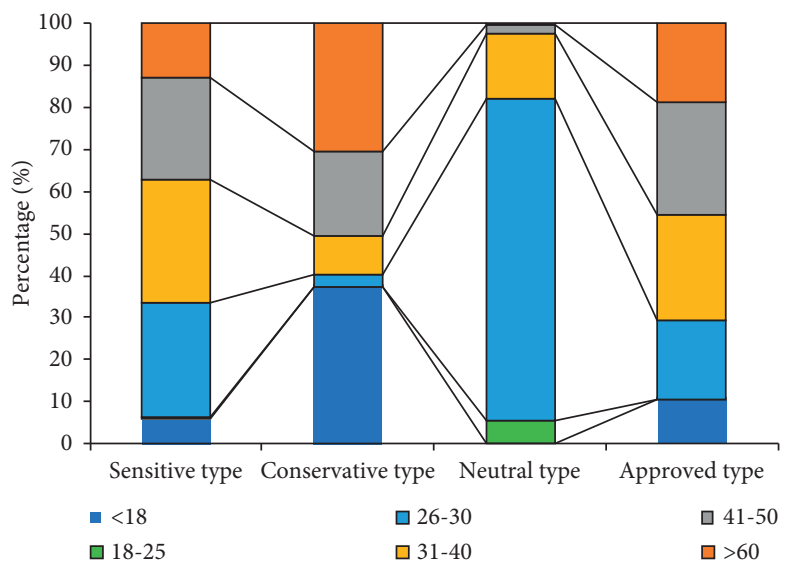

Figure 8: Age of drivers in the four segments.

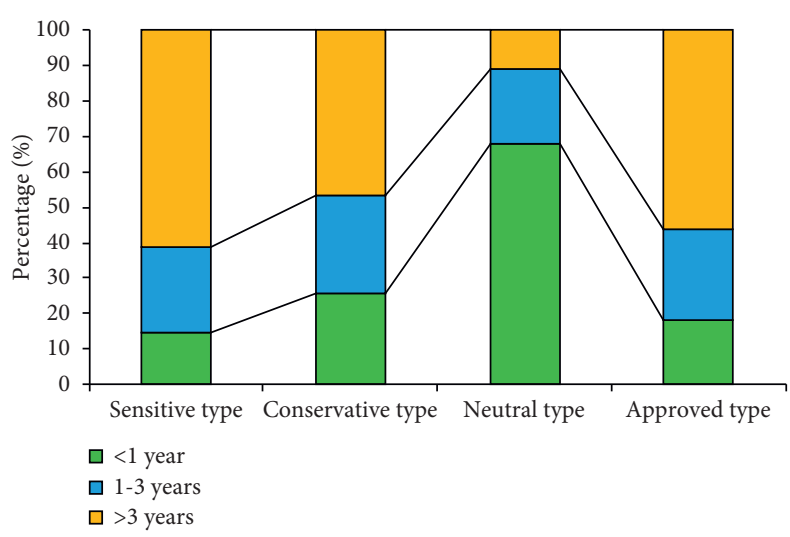

FIgURE 9: Driving experience of drivers in the four segments.

to the government and the media is basically the same as segment 2. The expectation for reduced parking fees is comparable to segment 1 , lower than segment 4 but higher than segment 2 , which is why we call it the "neutral type." Members of this segment are more often people younger than 25 years of age $(76.4 \%)$ and more often have driving experience within 1 year (67.6\%), which is also consistent with the distribution of age. Their average educational background is slightly lower than that of segment 1 but much higher than that of segments 2 and 4, and their monthly income is less than 5,000 yuan (90.5\%), so it can be inferred that this group may be college students or newly 


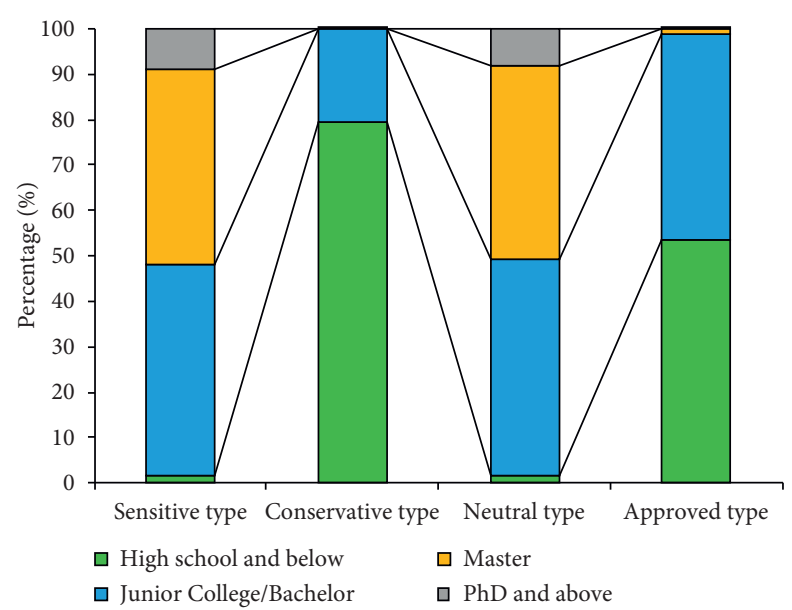

Figure 10: Education level of drivers in the four segments.

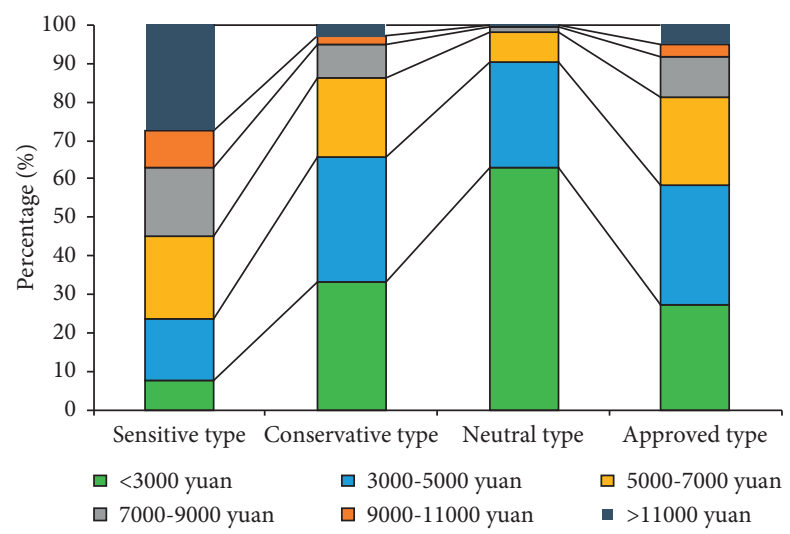

Figure 11: Income of drivers in the four segments.

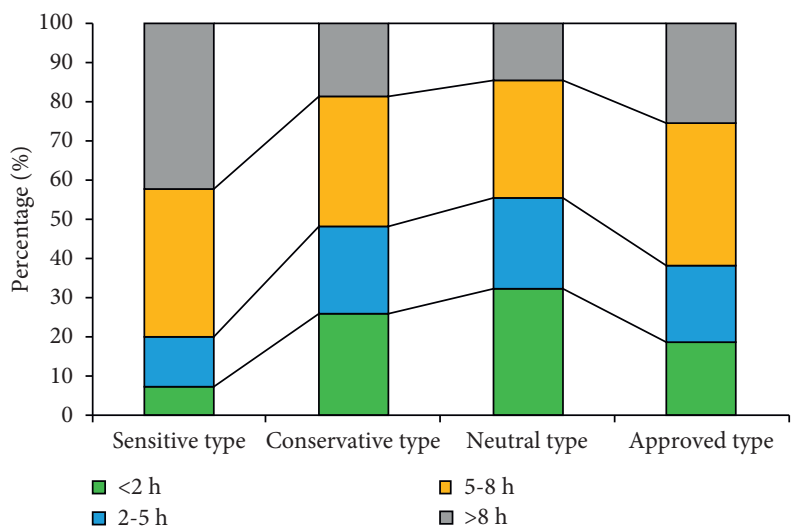

Figure 12: Parking time of drivers in the four segments.

graduated workers. In addition, they also have the lowest amount of parking time and the lowest frequency of driving trips, which reinforced our above hypothesis.

Segment 4 (9.9\% of the respondents) has the highest score among all psychological factors. This type of driver has the smallest percentage. People in this segment are generally confident in their ability to control new things and are also willing to respond to the call of the government and the media. $82 \%$ of the drivers in this group tend to "replace long distances for lower costs," which also reflects that they are very appreciative of shared parking projects, so we call it the "approved type." In this segment, their ages are evenly distributed, their educational backgrounds are concentrated in undergraduates and below (98\%), and their monthly 


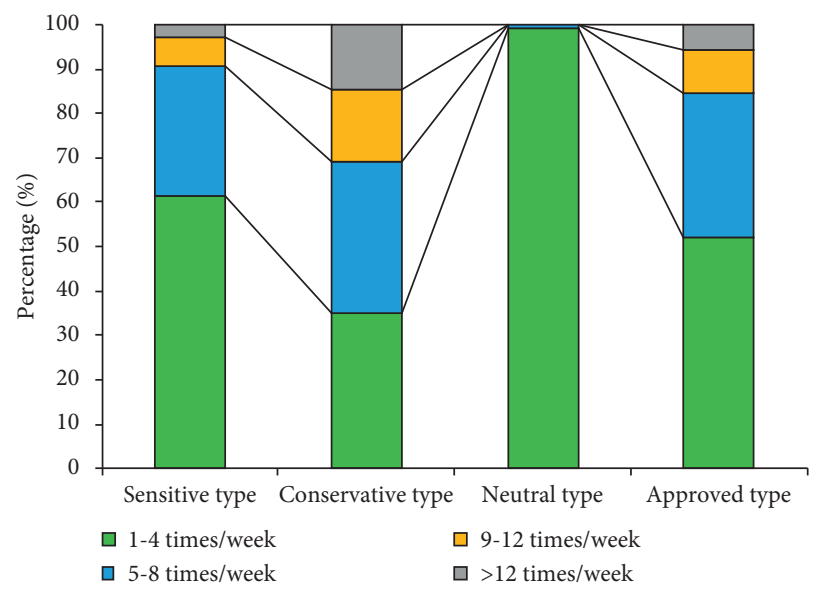

FIgURE 13: Driving frequency of drivers in the four segments.

income is concentrated below 9000 yuan. In addition, their driving frequency and parking time are both higher than segment 1 and lower than segment 2 .

\section{Conclusions and Discussion}

In this paper, we use the output of the MIMIC model as the input variables of LCM to explore the SPUI of drivers considering individual heterogeneity. The results showed that the surveyed driver groups can be divided into four segments: sensitive type (36\%), conservative type (29.6\%), neutral type (24.5\%), and approved type (9.9\%). In exploring those characteristics, we can better understand "the respective natures of the four segments." This study contributes to the literature by providing first-hand insights into SPUI of different categories of drivers.

Firstly, the multiple indicator multiple cause model was used to explore the relationship between psychological factors, personal attributes, travel characteristics, and SPUI. The research shows the following: (1) The extended theoretical model has good explanatory power for SPUI, and SPUI is directly affected by perceived risk (PR), behavioral habit $(\mathrm{BH})$, social influence (SI), facilitating conditions (FC), and effort expectancy (EE), while performance expectancy (PE) have no significant effect on SPUI. Among them, FC has the largest effect and PR has the smallest effect on SPUI. (2) Personal attribute variables including age, education level, monthly income, driving experience and driving frequency, and parking time in travel characteristics all have a significant influence on psychological variables.

Secondly, based on the analysis results of MIMIC, this paper uses LCM to explore the SPUI of different types of drivers from a microperspective. According to individual attributes, travel characteristics, and psychological factors, the potential classes of drivers are analyzed and simulated. Ten observation variables are used including age, education level, monthly income, driving experience, driving frequency, parking time, confidence in the control of shared parking systems (EE), response to the government and media (SI), perceived cost effectiveness (PE), and "long distance in exchange for less parking fees" tendency (FC).
Finally, the surveyed driver groups are divided into four segments: sensitive type (36\%), conservative type $(29.6 \%)$, neutral type $(24.5 \%)$, and approved type (9.9\%). The results show that for different types of drivers, their SPUI is closely related to personal attributes, travel characteristics, and psychological factors. Therefore, in order to attract drivers to choose shared parking, it is recommended that managers or operators can start with psychological factors, such as effort expectations, facilitating conditions, performance expectancy, and social influence.

More targeted measures can be implemented for different categories of drivers:

(1) For the first segment (sensitive type), they are more optimistic about the potential economic benefits of shared parking, which may be due to their higher average educational level and stronger acceptance of emerging things, and are exposed to a wider range of online information, so they are more susceptible to government and media influence than segment 2 and segment 3. It is not difficult for shared parking operators to attract users from this largest proportion of the drivers through various promotional methods, such as providing incentives for demanders and suppliers. At the same time, government-level countermeasures are very important to substantially promote dominoreaction. The government can introduce policies and regulations to encourage the development of shared parking, thereby stimulating the development of the shared parking industry.

(2) For the second segment (conservative type), their attitude toward shared parking is more conservative, less susceptible to the influence of the government and the media, and more rational than other segments, but their confidence in the control of the shared parking system is less than that of segments 1 and 4. The perceived potential economic benefit is the smallest among the four segments. Therefore, saving more parking fees may be the most important point to attract them. Reasonable parking fees are 
determined, and the negative impact of shared parking fees is reduced on them. For example, those who use shared berths flexibly or who have little parking demand can charge parking fees according to the parking time or the number of use times. For those who use shared parking spaces for a long time and have stable demand, a monthly or yearly fee with preferential rates can be adopted.

(3) For the third segment (neutral type), they have the least confidence in the control of the shared parking system. Therefore, creating a convenient, simple, and fully functional shared parking operating system may be the most important measure to attract them. However, since most of the available commercial maps cannot provide guidance in residential areas, it is important to display the turn-by-turn navigation function and detailed maps of the vacant parking spaces. In addition, some studies advocate the application of ergonomic principles in system design to make it more humane [73]. Finally, well-designed instruction manuals and training courses may help develop users' sense of self efficacy and ability to use technology [74]. These measures may help to improve users' technical compliance.

(4) For the fourth segment (approval type), they are very optimistic about the economic benefits of using shared parking. $82 \%$ of drivers have a strong intention to save parking fees even if the walking distance is increased. This group may have been exposed to the actual shared parking projects or in areas with high parking pressure. Therefore, the potential target areas of shared parking projects can be explored according to their spatial distribution characteristics.

However, this study inevitably has limitations that need to be resolved. Firstly, this study only considered the impact of latent variables and individual socioeconomic characteristics on the SPUI in residential areas and did not consider the impact of variables such as parking fees and walking distance, which is crucial for operators to determine reasonable prices. Secondly, this study explores the SPUI rather than the actual user behavior. In the future, the research can be extended to the investigation of the factors affecting actual use behavior. Thirdly, it is more valuable to jointly analyze the factors that affect the participation of suppliers and demanders in shared parking programs. This may promote better cooperation and matching between the two sides.

\section{Data Availability}

The data used to support the findings of this study are available from the corresponding author upon request.

\section{Conflicts of Interest}

The authors declare that there are no conflicts of interest regarding the publication of this paper.

\section{Acknowledgments}

This research was funded by the National Natural Science Foundation of China (No. 71971005) and the project was sponsored by Beijing Municipal Natural Science Foundation (No. 8202003). The supports are gratefully acknowledged.

\section{References}

[1] Beijing Transportation Development Research Institute, 2020 Annual Report on Beijing Transportation Development, Beijing Research Institute of Transportation Development, Beijing, China, 2020.

[2] Beijing Municipal Commission of Communications, Beijing Parking Resources Survey Report, Beijing Municipal Commission of Communications, Beijing, China, 2017.

[3] R. Arnott and J. Rowse, "Modeling parking," Journal of Urban Economics, vol. 45, no. 1, pp. 97-124, 1999.

[4] D. C. Shoup, "Cruising for parking," Transport Policy, vol. 13, no. 6, pp. 479-486, 2006.

[5] D. Ayala, O. Wolfson, B. Xu, B. Dasgupta, and J. Lin, "Parking slot assignment games," in Proceedings of the 19th ACM SIGSPATIAL International Conference on Advances in Geographic Information Systems, pp. 299-308, Chicago, IL, USA, November 2011.

[6] Y. Cai, J. Che, C. Zhang, and B. Wang, "A parking space allocation method to make a shared parking strategy for appertaining parking lots of public buildings," Sustainability, vol. 11, no. 1, p. 120, 2019.

[7] Q. Yan, T. Feng, and H. Timmermans, "Investigating private parking space owners' propensity to engage in shared parking schemes under conditions of uncertainty using a hybrid random-parameter logit cumulative prospect theoretic model," Transportation Research Part C: Emerging Technologies, vol. 117, Article ID 102776, 2020.

[8] P. Zhao, H. Guan, P. Wang, and H. Yan, "Evaluation of environmental benefits caused by reservation-based shared parking: a case study of Beijing, China," IEEE Access, vol. 9, pp. 3744-3751, 2021.

[9] W. Zhang, Y. Su, J. Dai, and L. Wang, "Distributing model for shared parking in the residential zones," Journal of Transportation Systems Engineering and Information Technology, vol. 19, no. 1, pp. 89-96, 2019.

[10] X. Zhou, Empirical Study on Sharing Willingness and Choosing Intention of Private Lots, Nanjing University, Nanjing, China, 2018.

[11] H. Zhu, H. Guan, Y. Han, and W. Li, "A study of tourists' holiday rush-hour avoidance travel behavior considering psychographic segmentation," Sustainability, vol. 11, no. 13, p. 3755, 2019.

[12] S. Haustein, M. Thorhauge, and E. Cherchi, "Commuters' attitudes and norms related to travel time and punctuality: a psychographic segmentation to reduce congestion," Travel Behaviour and Society, vol. 12, pp. 41-50, 2018.

[13] S. Choi, J. Ko, and D. Kim, "Investigating commuters' satisfaction with public transit: a latent class modeling approach," Transportation Research Part D: Transport and Environment, vol. 99, Article ID 103015, 2021.

[14] C. M. Peterson, T. F. Nelson, and M. A. Pereira, "Driver speeding typologies by roadway behaviours and beliefs: a latent class analysis with a multistate sample of U.S. adults," Transportation Research Part F: Traffic Psychology and Behaviour, vol. 81, pp. 373-383, 2021. 
[15] A. Rahimi, G. Azimi, H. Asgari, and X. Jin, "Adoption and willingness to pay for autonomous vehicles: attitudes and latent classes," Transportation Research Part D: Transport and Environment, vol. 89, Article ID 102611, 2020.

[16] J. Xie, X. Ye, Z. Yang et al., "Impact of risk and benefit on the suppliers' and managers' intention of shared parking in residential areas," Sustainability, vol. 12, no. 1, p. 268, 2019.

[17] A. Wang, H. Guan, Z. Qin, and J. Zhu, "Study on the intention of private parking space owners of different levels of cities to participate in shared parking in China," Discrete Dynamics in Nature and Society, vol. 2021, Article ID 9955686, 16 pages, 2021.

[18] A. Wang, H. Guan, Y. Han, and Y. Cao, "Private parking space sharing intention in China: an empirical study based on MIMIC model," Discrete Dynamics in Nature and Society, vol. 2021, Article ID 9283686, 13 pages, 2021.

[19] J.-K. Liang, T. Eccarius, and C.-C. Lu, "Investigating factors that affect the intention to use shared parking: a case study of Taipei City," Transportation Research Part A: Policy and Practice, vol. 130, pp. 799-812, 2019.

[20] N. Lalani, "Evaluating shared parking for new developments," Public Works, vol. 115, no. 2, p. 64, 1984.

[21] T. Litman, "Parking management best practices," Planning, vol. 72, no. 9, pp. 40-45, 2006.

[22] C. Shao, H. Yang, and Y. Ke, "A simple reservation and allocation model of shared parking lots," Transportation Research Part C: Emerging Technologies, vol. 71, pp. 303-312, 2016.

[23] M. Iman and A. Hamid, "Applying shared-parking turn-time (SPPC) model and geographic information system in the supply and demand analysis of parking space," Malaysian Journal of Real Estate, vol. 1, no. 2, pp. 57-76, 2006.

[24] O. T. T. Kim, N. D. Tri, N. H. Tran, and C. S. Hong, "A shared parking model in vehicular network using fog and cloud environment," in Proceedings of the 2015 17th Asia-Pacific Network Operations and Management Symposium (APNOMS), pp. 321-326, Busan, Repulic of Korea, August 2015.

[25] H. Xiao, M. Xu, and Z. Gao, "Shared parking problem: a novel truthful double auction mechanism approach," Transportation Research Part B: Methodological, vol. 109, pp. 40-69, 2018.

[26] P. Zhao, H. Guan, and P. Wang, "Data-driven robust optimal allocation of shared parking spaces strategy considering uncertainty of public users' and owners' arrival and departure: an agent-based approach," IEEE Access, vol. 8, Article ID 24182, 2020.

[27] A. Glazer and E. Niskanen, "Parking fees and congestion," Regional Science and Urban Economics, vol. 22, no. 1, pp. 123-132, 1992.

[28] R. G. Lipsey and K. Lancaster, "The general theory of second best," The Review of Economic Studies, vol. 24, no. 1, pp. 11-32, 1956.

[29] J. Chen and K. Xie, "Dynamic allocatin model and effect evaluation of campus shared-use parking in central city," China Journal of Highway and Transport, vol. 28, no. 11, pp. 104-111, 2015.

[30] K. He, J. Zhang, and Y. Zeng, "Households' willingness to pay for energy utilization of crop straw in rural China : Based on an improved UTAUT model," Energy Policy, vol. 140, Article ID 111373, 2020.

[31] G. Sheng, B. Yue, and S. Gong, "A research on consumer's intention to use shared bicycles continuously-based on extended model of TAM theory," Journal of Northeastern University, vol. 21, no. 6, pp. 567-574, 2019.

[32] V. Venkatesh, M. G. Morris, G. B. Davis, and F. D. Davis, "User acceptance of information technology: toward a unified view," MIS Quarterly, vol. 27, no. 3, pp. 425-478, 2003.

[33] J. Chen, R. Li, M. Gan, Z. Fu, and F. Yuan, "Public Acceptance of Driverless Buses in China: An Empirical Analysis Based on an Extended UTAUT model," Discrete Dynamics in Nature and Society, vol. 2020, Article ID 4318182, 13 pages, 2020.

[34] R. Madigan, T. Louw, M. Wilbrink, A. Schieben, and N. Merat, "What influences the decision to use automated public transport? Using UTAUT to understand public acceptance of automated road transport systems," Transportation Research Part F: Traffic Psychology and Behaviour, vol. 50, pp. 55-64, 2017.

[35] J. Lan and D. Zhu, "Acceptance and use behavior of sustainable transport: based on a survey of carsharing in Shanghai," China Population, Resources and Environment, vol. 26, no. 11, pp. 98-105, 2016.

[36] C. Chen and X. Li, "Research on the effect factors of customer use intention of shared bicycles," Chinese Journal of Management, vol. 15, no. 11, pp. 1601-1610, 2018.

[37] H. Aarts, B. Verplanken, and A. V. Knippenberg, "Predicting behavior from actions in the past: repeated decision making or a matter or habit?" Journal of Applied Social Psychology, vol. 28, no. 15, pp. 1355-1374, 1998.

[38] J. Chen, Q. Chen, and H.-P. Li, "Psychological influences on bus travel mode choice: a comparative analysis between two Chinese cities," Journal of Advanced Transportation, vol. 2020, no. 2, 9 pages, Article ID 8848741, 2020.

[39] T. Teichert, E. Shehu, and I. V. Wartburg, "Customer segmentation revisited: the case of the airline industry," Transportation Research Part A: Policy and Practice, vol. 42, no. 1, pp. 227-242, 2008.

[40] G. I. Crouch, T. Huybers, and H. Oppewal, "Inferring future vacation experience preference from past vacation choice," Journal of Travel Research, vol. 55, no. 5, pp. 574-587, 2014.

[41] C. F. Xiong, H. Pratt, and L. Zhang, "On Ride-Sharing: A Departure Time Choice Analysis with Latent Carpooling Preference," Journal of Transportation Engineering, vol. 140, no. 8, 2014.

[42] W. H. Greene and D. A. Hensher, "A latent class model for discrete choice analysis: contrasts with mixed logit," Transportation Research Part B: Methodological, vol. 37, no. 8, pp. 681-698, 2003.

[43] S. Shelat, R. Huisman, and N. van Oort, "Analysing the trip and user characteristics of the combined bicycle and transit mode," Research in Transportation Economics, vol. 69, pp. 68-76, 2018.

[44] M. Yanagihara, N. Uno, and T. Nakamura, "Latent class Analysis for driving behavior on merging section," Transportation Research Procedia, vol. 6, pp. 259-271, 2015.

[45] J. Alegre, S. Mateo, and L. Pou, "A latent class approach to tourists' length of stay," Tourism Management, vol. 32, no. 3, pp. 555-563, 2011.

[46] C. Pronello and C. Camusso, "Travellers' profiles definition using statistical multivariate analysis of attitudinal variables," Journal of Transport Geography, vol. 19, no. 6, pp. 1294-1308, 2011.

[47] S. Haustein and M. Hunecke, "Identifying target groups for environmentally sustainable transport: assessment of different segmentation approaches," Current Opinion in Environmental Sustainability, vol. 5, no. 2, pp. 197-204, 2013. 
[48] J. T. Zhang, C. Jiao, and M. Q. Zhang, "Application of latent class Analysis in psychological research," Advances in Psychological Science, vol. 18, no. 12, pp. 1991-1998, 2010.

[49] B. Xu, Research on the ICLV Model of Intercity Travel Mode Selection, Beijing Jiaotong University, Beijing, China, 2018.

[50] S. Shu, Y. Bian, J. Rong, and S. Li, "Transition from driving to bicycling in short-distance travel based on MIMIC model," Journal of Beijing University of Technology, vol. 45, no. 10, pp. 998-1008, 2019.

[51] M. Hunecke, S. Haustein, S. Böhler, and S. Grischkat, "Attitude-based target groups to reduce the ecological impact of daily mobility behavior," Environment and Behavior, vol. 42, no. 1, pp. 3-43, 2010.

[52] P. Jing, J. Zhi-Cai, and Q. F. Zha, "Application of the expanded theory of planned behavior in intercity travel behavior based on MIMIC model," Journal of Industrial Engineering and Engineering Management, vol. 30, no. 4, pp. 61-68, 2016.

[53] F. Schneider and D. Enste, Shadow Economies Around the World-Size, Causes, and Consequences, IMF Working Papers, Washington, D.C, USA, 2000.

[54] H. Qiu, Latent Class Modeling Principles and Techniques, Educational Science Publishing House, Beijing, China, 2008.

[55] L. M. L. Bonilla and J. M. L. Bonilla, "Postmodernism and heterogeneity of leisure tourist behavior patterns," Leisure Sciences, vol. 31, pp. 68-83, 2009.

[56] C.-H. Wen and S.-C. Lai, "Latent class models of international air carrier choice," Transportation Research Part E: Logistics and Transportation Review:Logistics and Transportation Review, vol. 46, no. 2, pp. 211-221, 2010.

[57] S. Okazaki, S. Campo, L. Andreu, and J. Romero, "A latent class Analysis of Spanish travelers' mobile internet usage in travel planning and execution," Cornell Hospitality Quarterly, vol. 56, no. 2, pp. 191-201, 2015.

[58] E. Molin, P. Mokhtarian, and M. Kroesen, "Multimodal travel groups and attitudes: a latent class cluster analysis of Dutch travelers," Transportation Research Part A: Policy and Practice, vol. 83, pp. 14-29, 2016.

[59] X. H. Zeng, L. Xiao, and Y. B. Zhang, "Principle of latent class Analysis and case analysis," Health Statistics Department of Public Health School, vol. 30, no. 6, pp. 815-817, 2013.

[60] X. F. Ji and D. L. Li, "A model for segmentation of highway passenger groups based on latent class," Journal of Highway and Transportation Research and Development, vol. 36, no. 10, pp. 152-158, 2019.

[61] R. L. Tompson, C. A. Higgins, and J. M. Howell, "Personal computing: toward a conceptual model of utilization," MIS Quarterly, vol. 15, no. 1, pp. 125-143, 1991.

[62] I. Ajzen, "The theory of planned behavior," Organizational Behavior and Human Decision Processes, vol. 50, no. 2, pp. 179-211, 1991.

[63] I. Im, Y. Kim, and H.-J. Han, "The effects of perceived risk and technology type on users' acceptance of technologies," Information \& Management, vol. 45, no. 1, pp. 1-9, 2008.

[64] M.-C. Lee, "Factors influencing the adoption of internet banking: an integration of TAM and TPB with perceived risk and perceived benefit," Electronic Commerce Research and Applications, vol. 8, no. 3, pp. 130-141, 2009.

[65] H. Wang, R. Li, X. Wang, and P. Shang, "Effect of on-street parking pricing policies on parking characteristics: a case study of Nanning," Transportation Research Part A: Policy and Practice, vol. 137, pp. 65-78, 2020.

[66] Z. Pu, Z. Li, J. Ash, W. Zhu, and Y. Wang, "Evaluation of spatial heterogeneity in the sensitivity of on-street parking occupancy to price change," Transportation Research Part C: Emerging Technologies, vol. 77, pp. 67-79, 2017.

[67] D. George and P. Mallery, IBM SPSS Statistics 26 Step by Step: A Simple Guide and reference, Routledge, London, UK, 2019.

[68] S. Ahmad, N. Zulkurnain, and F. Khairushalimi, "Assessing the validity and reliability of a measurement model in structural equation modeling (SEM)," British Journal of Mathematics \& Computer Science, vol. 15, no. 3, pp. 1-8, 2016.

[69] G. Marcoulides, Modern Methods for Business Research, Psychology Press, New York, NY, USA, 1998.

[70] P. Cohen, S. G. West, and L. S. Aiken, Applied Multiple Regression/Correlation Analysis for the Behavioral Sciences, Psychology Press, London, UK, 2014.

[71] D. Pacifico and H. I. Yoo, "lclogit: a Stata command for fitting latent-class conditional logit models via the expectationmaximization algorithm," STATA Journal: Promoting communications on statistics and Stata, vol. 13, no. 3, pp. 625-639, 2013.

[72] C. C. Clogg, "Some latent structure models for the analysis of likert-type data," Social Science Research, vol. 8, no. 4, pp. 287-301, 1979.

[73] Y. Ning, M. Yan, X. S. Xu, Y. Li, and L. Li, "Shared parking acceptance under perceived network externality and risks: theory and evidence," Transportation Research Part A: Policy and Practice, vol. 150, pp. 1-15, 2021.

[74] J. A. Jacko, "Human Computer Interaction Handbook:," Fundamentals, Evolving Technologies, and Emerging Applications, CRC Press, Florida, FL, USA, Second edition, 2012. 